\title{
Practical Exploration of University-Enterprise Collaborative Talent Cultivation Based on "Excellent Engineer Education and Training Program"
}

\author{
Guangyu $\mathrm{Mu}^{1, *}$ Xue Wang ${ }^{1}$ \\ ${ }^{1}$ School of Management Science and Information Engineering, Jilin University of Finance \& Economics, Changchun, \\ Jilin 130117, China \\ *Corresponding author. Email: guangyumu@126.com
}

\begin{abstract}
In order to promote China to become a mighty country in engineering education, the Chinese Ministry of Education has executed the "Excellent Engineer Education and Training Program" (hereinafter referred to as EEETP) for nearly a decade. The purpose of this paper is to explore the impact of university-enterprise collaborative talent cultivation on the EEETP. Based on the above objectives, we take university-enterprise cooperation as the entry point of the EEETP, introduce the implementation status of university-enterprise collaborative talent cultivation in the context of the EEETP and analyze the reasons for the current situation. Then we elaborate the ideas of university-enterprise collaborative talent cultivation, and creatively construct the implementation path of computer science and technology talents training of Jilin University of Finance and Economics. Finally, we explore the specific reform measures of the EEETP, aiming to cultivate innovative and applied talents that meet the requirements of the time, and provide the theoretical support for the further development of the EEETP. The results show that the university-enterprise synergy talent training is the fundamental way to achieve the EEETP.
\end{abstract}

Keywords: Excellent Engineer Education, Engineer Training Program, University-enterprise cooperation, Talents cultivation

\section{INTRODUCTION}

The Chinese Ministry of Education launched the EEETP in June 2010, aiming to develop a group of high-quality engineering and technical talents who are oriented towards the industry, the future, and the world. Universityenterprise collaborative training mode is usually a " $3+1$ " training mode in which universities and enterprises work together. The training mode uses two different educational environments and resources, and adopts a reasonable combination of professional knowledge teaching and student participation in practical teaching [1]. Moreover, the operation mode focuses on cultivating students' engineering practice ability to form a talent education model with comprehensive quality and innovative ability. Therefore, a new model for collaboratively training talents between universities and enterprises is not only the fundamental task of the EEETP, but also the needs of China to promote higher engineering education reform. Since the EEETP was put forward, many universities have carried out cooperation with local enterprises on talent training, but the effect is not really ideal. There are still some problems in collaborative process that prevent the EEETP from achieving its maximum value. For how to effectively respond to the implementation of the EEETP, the research theme of this article is exploring the university-enterprise collaborative talent cultivation program.

\section{IMPLEMENTATION STATUS OF UNIVERSITY-ENTERPRISE COLLABORATIVE TALENT CULTIVATION BASED ON THE EEETP}

\begin{abstract}
The Chinese Ministry of Education launched the EEETP in order to solve the problem of "big but not strong, more but less refined" facing the engineering education in China. Since the program was implemented nine years ago, it has been distributed into three batches [2]. More than 200 universities have been selected into the program. Teachers and students of computer science and technology responded positively to the program. The computer major fully leveraged the advantages of both schools and enterprises to carry out university-enterprise cooperation. With the purpose of constructing an engineering practice education centre as corporate practice bases for the implementation of the program, we have successively signed university-enterprise cooperation agreements with AsiaInfo Technology (China) Company Limited, Watson Cooper (Beijing) Company Limited, Neusoft and Jilin construction bank. The university-enterprise cooperation bases actively build an internship and employment platform for students. Nearly $70 \%$ of students have
\end{abstract}


conducted internships in university-enterprise cooperation units. Through the establishment of the universityenterprise cooperation platform, multiple career paths have been established for computer students in our college. In other words, the employment pathways have been driven by the practice bases, which form the distinctive characteristics of our college's engineering specialty.

However, there are some inevitable and urgent problems during the implementation of the program. First, the collaborative work of university-enterprise talent training is insufficient. The EEETP advocates "double tutorial system", in which teachers in the school are mainly responsible for students' on-campus learning and corporate mentors are mainly responsible for student enterprises' learning. School teachers and enterprises mentors need to work closely together. As far as the computer major in this school is concerned, most of the students' graduation designs and thesis topics come from school tutors. The student's thesis guidance work is mainly completed with the participation of the school tutors, and the participation of enterprise mentors is seriously deficient.

In addition, the construction of practical teaching bases is difficult. At present, practical teaching in colleges mostly stays on the virtual level, such as simulation laboratories and virtual experiments. Due to the lack of investment and construction of practical teaching bases, the school faces the embarrassing situation of "active schools and indifferent enterprises" in the implementation of the work. Simultaneously, there are many problems such as irregular management and low participation of enterprises, which make it difficult for college students to practice [3].

\section{CAUSES OF PROBLEMS IN UNIVERSITY-ENTERPRISE COLLABORATIVE CULTIVATION}

\subsection{Unreasonable Mechanism of the University-Enterprise Collaborative Talent Cultivation}

Most of the university-enterprise cooperative education is a mere formality and has not reached the real deep integration. Universities lack a set of reasonable university-enterprise collaborative talent training mechanisms. In the practice section of universities, more attention is given to how to use the resources of cooperative enterprises. Universities only emphasize the obligation of enterprises to support higher education, and rarely consider the cultivation and selection of reserve talents, service requirements and other needs. Both parties have no effective mechanism of talent training. The short practice time and rigid practice content have resulted in little improvement of students' practice ability. The effect of the internship is extremely limited, and the company cannot availably promote the cultivation of applying innovative talents. Thus, it is arduous for us to implement the program [4]

\subsection{Biased Setting of Theoretical and Practical Periods}

The traditional talent training mode has a tendency of "emphasizing theory and neglecting practice", which is slightly different from the talent training mode of the EEETP [5]. Schools and enterprises have not fully entered into a cooperative role, and the curriculum system is still basically set up by the school. Resulting from a long-term impact of exam-oriented education, engineering colleges pay attention to the imparting of theoretical and engineering basic knowledge. The participation of enterprises is relatively low, so it is difficult for corporate practical teaching to penetrate into the curriculum system [6]. The cultivation of students' experimental and practical skills is neglected. Enterprises need to spend a lot of time and money to retrain students, which has greatly limited the implementation of the EEETP.

\subsection{Insufficient Practical Ability of the Teaching Staff}

Currently, there is a trend for engineering teachers in universities to weaken engineering. Most of the highly educated engineering teachers have received their bachelor's degree, master's degree and doctor's degree, but they do not have the experience of working in enterprises. A teacher without practical experience is unable to guide his students well. They can only move from theory to theory, which results in students only mastering theory but not innovation and practice [7]. At the same time, the academic atmosphere of colleges is also showing a trend of engineering weakening. Colleges attach more importance to teachers' theoretical foundation and academic level, and lack enough requirements on teachers' engineering experience and practical ability. Therefore, students trained by teachers with weak practical level will be unable to meet the needs of enterprises in the future.

\section{THE IMPLEMENTATION PATH OF UNIVERSITY-ENTERPRISE COLLABORATIVE TALENT CULTIVATION FOR COMPUTER SCIENCE AND TECHNOLOGY MAJOR OF JILIN UNIVERSITY OF FINANCE AND ECONOMICS}

The computer major in our school, as one of the pilot majors in the EEETP of the Chinese Ministry of Education, has performed in-depth practice and research according to the national training standard of the EEETP. In terms of internationalization objectives, we focus on 
cultivating graduates with internship experience in global IT companies. In terms of engineering goals, we lay emphasis on the basic theory and engineering practice, strengthen the construction of university-enterprise cooperation bases, and concentrate on training students' engineering consciousness. In the aspect of financial informatization, we pay attention to the development and application ability of financial business process reengineering, the decision-making ability of information technology and the risk prevention capability for cultivating innovative compound talents.

\subsection{Innovating the Talent Training Mode}

Our college has continuously explored the reform of the talent training model over the years, and gradually established a computer major with financial characteristics that are "relying on the advantages of the disciplines, the linkage of majors, the cooperation of government, school, and enterprise, the promotion of international cooperation and scientific research". The new model of talent training is shown in Figure 1. In the teaching procedure, we enforce the double tutorial system which uses the students' innovation and engineering ability as the evaluation index. We clarify the talent training objectives, professional discipline structure and talent social demand positioning in order to measure up the purpose of cultivating students' comprehensive ability.

\subsubsection{Positioning talent training goals}

With the training goal of "high quality international engineering information technology talents with wide calibre, thick foundation and innovative spirit", we highlight the characteristics of financial informatization, and foster a reasonable knowledge structure and a solid engineering theoretical foundation for students.
Relying on the advantageous discipline resources such as economics, finance, and accounting of Jilin University of Finance and Economics, we take the disciplines of management science and information engineering as the core to bring about multidisciplinary crossing and integration.

\subsubsection{Positioning the social needs of talents}

We proceed from internationalization demand of higher education, actively adapt to national information development strategies and meet the social needs of large enterprises in finance and economics. With computer engineering technology as our main goal, we bring up professional talents with an international vision and the industrial development demand.

\subsection{Restructuring the Curriculum System}

In the professional talent training program, the teaching plan is divided into the theoretical teaching and the practical teaching.

\subsubsection{Improving the theoretical teaching system}

The theoretical teaching system consists of six modules: general basic course, basic discipline course, specialized course, public elective course, general elective course and practical course. The curriculum is divided into three stages. The first stage is the basic education. The second stage is the specialized learning, which provides students with professional education according to the principle of "fine specialty and multi-direction". The third stage is the capacity development and promotion. It mainly focuses on professional practice courses and enterprise internships. According to the requirements of the enterprise, corresponding practical courses are set up, and the practical cases of enterprises are seamlessly embedded into the training program.

\subsubsection{Positioning professional discipline structure}

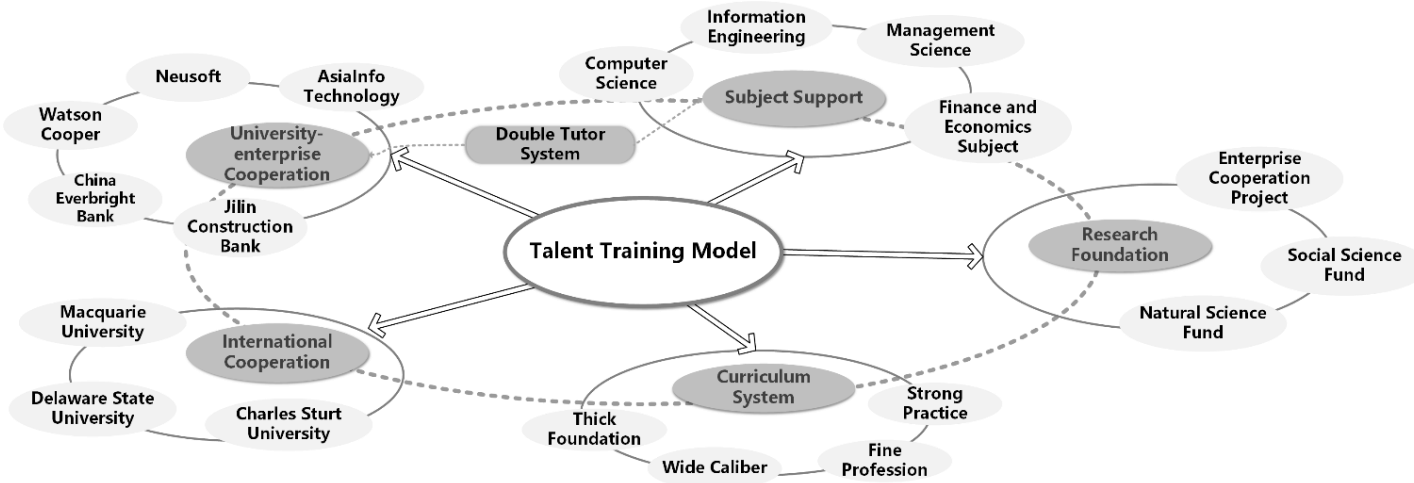

Figure 1 The pattern of training innovative talents 


\subsubsection{Innovating the practice teaching system}

The practice teaching system is indispensable for computer science and technology specialty. The practice periods account for $25 \%$ of the total undergraduate courses. The practical course consists of three types: basic practice, professional practice and comprehensive practice. Through basic practice, students can improve the skills of cognitive society and teamwork, and lay the foundation for professional learning. Professional practice can deepen students' specialty knowledge and promote students' scientific thinking and innovation ability. Comprehensive practice emphasizes students' participation in the actual projects on the school's practice bases [8]. Thesis topics for undergraduates and graduates are derived from actual corporate projects, and are dually guided by on-campus tutors and corporate tutors. Finally, the comprehensive practice not only strengthens the theoretical level but also highlights the practical skill.

\subsection{Constructing Teams of Teachers Inside and Outside the School}

\subsubsection{Building a "double-qualified" professional teacher team}

The average age of teachers in our college is about 40 years old. $80 \%$ of them have doctor's degree. Many of them have obtained projects from the National Natural Science Foundation and National Social Science Foundation. During the university-enterprise cooperation, on the one hand, our college selects young teachers to work and study in the enterprise with pay. They participate in the scientific research and management activities of the enterprise to cultivate their engineering experience. On the other hand, relying on the scientific research, we introduce the projects into the cooperation programs to improve the teaching ability of teachers. This not only solves the practical engineering problems, but also is an effective way to train teachers' corporate experience.

\subsubsection{Inviting guest professors and enterprise engineers}

Our college has invited well-known professors at home and abroad as guest professors in our college. Guest professors regularly come to the college to conduct academic exchanges with teachers and students, bring the latest academic achievements and engineering information in the professional field, and lay a solid foundation for cultivating engineering talents in computer science [9]. At the same time, we provide a platform for corporate employees to enter the classroom to teach enterprise cases and share practical experience on the university-enterprise cooperation base. These business cases greatly enrich the breadth and depth of teaching, make up for the lack of practical experience of our teachers, and rapidly improve the quality of teaching.

\subsection{Strengthening the Practice Teaching Base Inside and Outside the School}

The practical teaching of computer specialty is distributed in campus practice base and off-campus practice base.

\subsubsection{Campus practice teaching base}

The primary task of the on-campus practice teaching base is to serve the teaching of colleges. Our school has initially formed innovative experimental teaching platforms where senior engineers can teach business cases and share practical experience. Once students register, the courses of "Computer Software Industry Development" are arranged every semester, which are collaboratively undertaken by high-level teachers and senior enterprise experts with many years of software engineering experience. The latest achievements of industry and academia are timely added into the teaching content of the courses to improve students' ability of teamwork and practical innovation. The construction of campus practice teaching base plays an important role in the reform of practice teaching and improving the students' ability to combine theory with practice.

\subsubsection{Enterprise practice teaching base}

Enterprise teaching includes comprehensive practice, short-term internship in software engineering courses, graduation design and other links, as shown in Figure 2.
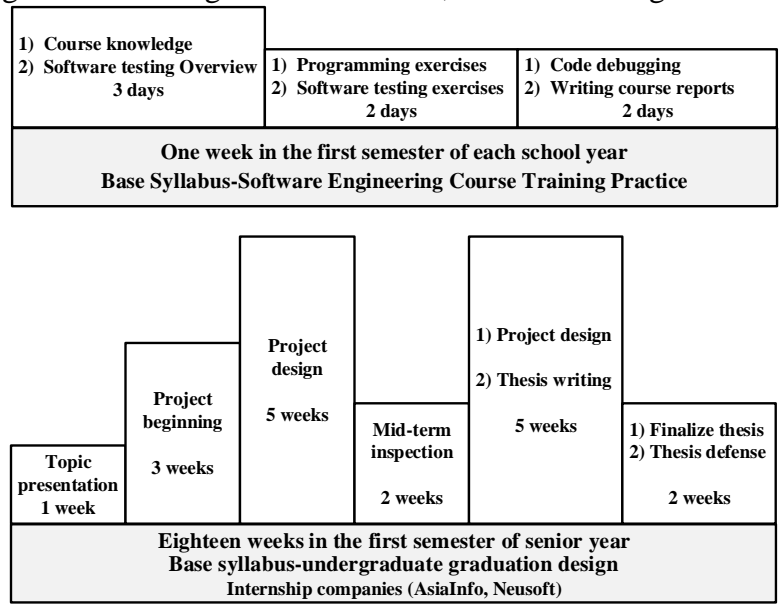

Figure 2 The pattern of off-campus base syllabus

In the construction of the university-enterprise cooperation bases, enterprise teaching is closely integrated with oncampus teaching, and interspersed with the whole learning 
cycle of students. The cumulative learning time is not less than one year. Enterprises provide internship practice platforms for students. Students and enterprise employees collaboratively develop projects to achieve the integration of theoretical knowledge and practical skills. The establishment of the university-enterprise cooperation base has created favourable conditions for the employment of undergraduates of our college and provided an effective guarantee for the training of enterprise order-type talents. By 2019, hundreds of graduates of our college have entered the university-enterprise cooperation base for practice, internship and employment.

\section{CONCLUSION}

Taking the EEETP as an opportunity, our college energetically explores the implementation path of the university-enterprise collaborative talent training. Following the principle of win-win cooperation, we aim to improve the engineering practice and innovation ability of college students, which provide theoretical support for the further adjustment of the EEETP.

\section{ACKNOWLEDGMENT}

The research was supported in part by the National Social Science Foundation of China under Grant No.19BJY246, in part by the Natural Science Foundation of Jilin Provincial Science \& Technology Department under Grant No.20190201186JC and in part by the Science and Technology Foundation of Jilin Provincial Education Department under Grant No. JJKH20190725KJ.

\section{REFERENCES}

[1] Zhenying Liu, Zifang Xu, Linyi Zheng, Establishment of university-enterprise collaborative talent training model based on Excellence Program, in: Guangzhou Chemical, vol. 44(16), 2016, pp. 194-195.

[2] Wei Teng, Zhen Liu, Jing Fang, Research on innovative talents cultivation mechanism of universityenterprise cooperation for IoT engineering specialty facing "Excellence Program", in: Journal of Science Teaching, vol. 9, 2015, pp. 37-38+40.

[3] Jun Sun, Guojin Chen, Practical difficulties and countermeasures of school-enterprise cooperation in implementing the "Excellence Program", in: Journal of Jilin Province Institute of Education (Mid-term), vol. 31(06), 2015, pp. 37-39+73.
[4] Yi Jiang, Investigation on the status quo of the implementation of the "Excellent Engineer Education and Training Program" and its countermeasures--taking $\mathrm{Y}$ university as an example, Yangzhou University, 2016.

[5] Shijie Su, Wenxian Tang, Jiyang Qi, Honggen Zhou, The Construction of a university-enterprise winwin engineering practice teaching base for the "Excellent Program", in: Experimental Technology and Management, vol. 33(01), 2016, pp. 222-225.

[6] Wei Wei, Hongliu Xia, Zhijun Wang, Jianmin Hua, The exploration and practice of the mode of graduation design guided by the school-enterprise cooperation of "excellence program", in: Higher Architectural Education, vol. 28(06), 2019, pp. 100106.

[7] Chenglin Zhu, Yuzhu Hua, Research on the training of engineering talents in China under the background of new engineering construction -- based on the perspective of literature review, in: Yuejiang Academic Journal, vol. 11(05), 2019, pp. 94$100+123$.

[8] Xiaobing Yang, Research on talent cultivation of "Excellence Program" in universities under the background of new engineering, in: Educational Theory and Practice, vol. 38(33), 2018, pp. 6-8.

[9] Xiaoping Wu, Shubo Liu, Jun Zhou, Yuling Hu, Exploration and practice of computer science and technology outstanding engineer training system for new engineering, in: Computer Education, vol. 2, 2020, pp. 5-7. 